\title{
V. Woolf's Literary Interpretation of the Body without Limits: A Conceptual Study
}

\author{
By Iryna Galutskikh*
}

\begin{abstract}
This research focuses on the specific features of literary representation of human body in the literary texts of the English modernist writer Virginia Woolf. The research is aimed at the analysis of linguistic aspects of corporeality as the basis of imagery formation in literary text by means of studying the ways of conceptualization of the HUMAN BODY domain in $V$. Woolf's literary prose. The aim is realized with the methods of semantic and cognitive types of linguistic analyses applied, which imply the process of reconstruction of conceptual metaphors in the text. The results obtained demonstrated that HUMAN BODY is metaphorically represented as the BODY WITHOUT LIMITS by means of the images of a "deformed" or "shapeless" BODY, which in $V$. Woolf's figurative interpretation reveal the correlation of physical "losing limits" with the depressive and unstable states of mind and soul of the individual.
\end{abstract}

\section{Introduction}

The phenomenon of human body has been the focus of attention of multiple scientific paradigms since ancient times. Human body has been in the spotlight of numerous investigations in biology, anatomy, physiology, chemistry as a biological entity as well as in psychology, philosophy, anthropology, sociology, linguistics, literary studies, culture studies, cognitive science, etc. as a socio-cultural phenomenon (Alkali et al., 2013; Gibbs, 2006; Lixia, 2011; Ostry, 2008; Pease, 1981; Ziemke et al., 2007).

Analytical study of the works proved the vagueness and obscurity of the term "body" itself. Its difficulty derives in part from the fact that it is thought of in various ways. The wide range of interdisciplinary and multiaspectual scientific approaches stipulated a considerable debate as to what the term body actually means.

Whereas in natural sciences this concept is more clearly defined, understood as a physically determined entity, the entire structure of a human organism, consisting of a torso, its parts, limbs and the organ systems of the individual complying to the laws of existence, functioning and development of a living being, in humanities the term human body is much more ambiguous and not so self-evident.

*Associate Professor, Zaporizhzhya National University, Ukraine. 
Throughout the $\mathrm{XX}^{\text {th }}$ century different manifestations of human body are analyzed in a variety of discourses. Being not confined to its biological and physiological dimensions only, human body attracts much attention of philosophers, anthropologists, sociologists, linguists, etc. and nowadays it remains the central object of interdisciplinary research, being one of the key concepts of modern philosophic thought.

Gradually it extends the boundaries of its understanding, being interpreted in the conceptions of a "phenomenological body" of E. Husserl (Husserl, 1982) and M. Merleau-Ponty (Merleau-Ponty, 1999), "social body" of M. Foucault (Foucault, 1970; 1978) and "body without organs" of G. Deleuze and F. Guattari (Deleauze \& Guattari, 1972), "textual body" of R. Barthes (Barthes, 1989), etc., as the sphere of activation of various social and discursive codes.

Despite the fact that significant results of its research have been obtained till present, there is still a lot of questions concerning human body, one of them being the question about the body limits and its relation to reality. It was raised in poststructuralist theory (Nancy, 2008; Deleuze \& Guattari, 1972) and is still open to debate.

While scholars do not leave the attempts to provide a profound research of corporeality and human body phenomenon, the body as the element of culture undergoes changes conforming to the chronological period.

In the $X X^{\text {th }}$ century corporality gets significant foregrounding in the culture forms (literature, painting, sculpture, cinematography, etc.) where human body appears not only as an object of reflection, but a means of image formation as well.

These factors make literary corporeality the object of study with a special appeal to a researcher. It implies the study of the concept of human body affected by the socio-cultural factors viewed through the prism of a certain literary text or a corpus of texts of a particular author or literary trend.

In this article the poetic interpretation of human body in the literary texts of the English modernist writer Virginia Woolf is studied.

The material of the research is the corpus of literary texts by Virginia Woolf, among them being her novels "The Waves", "Mrs. Dalloway", "To the Lighthouse", "Between the Acts", "Orlando".

Judging from the previously completed linguo-cognitive analysis of bodily images in V. Woolf's literary prose (Galutskikh, 2013), she interpreted corporeality through the prism of her specific vision. It finds reflection in the imagery space of her novels, where human body appears as "deformed" or "shapeless", that implies having open, indefinite or permeable limits.

The article is aimed at the research of the ways of imagery conceptualization of HUMAN BODY domain in V. Woolf's literary prose and the means of literary representation of the image of the BODY WITHOUT LIMITS.

The aim is realized with the methods of semantic and cognitive types of linguistic analyses applied, which imply the process of reconstruction of conceptual metaphors in the text. The methodological grounds of the research 
is the theory of conceptual metaphor (Lakoff \& Johnson, 1980; Kövecses, 2002) and the theory of conceptual integration (Fauconnier \& Turner, 2003).

The results obtained of the conceptual analysis revealed the specific vision of the HUMAN BODY in Virginia Woolf's literary prose represented by the image of the BODY WITHOUT LIMITS and its role in the formation of the conceptual and imagery space of her novels.

\section{Non-Integral Body}

Thus, the author refers to the image of the HUMAN BODY, which is poetically interpreted as the BODY WITHOUT LIMITS, to depict feelings and psychological state of her characters that is usually pessimistic and full of discomfort.

Normally the limits of the body in its physical sense as well as its shapes are delineated by skin, though in the metaphorical vision of the modernist writer the HUMAN BODY is represented as being deprived of these limits as a result of changing its shape, size, consistency, being deformed, becoming invisible, etc. and, thus, altering its lineaments or being altogether annihilated.

For example, in some fragments of the text the HUMAN BODY is treated as a part of a biomass. This understanding of the HUMAN BODY concept is generalized by means of the conceptual metaphors HUMAN BODY IS A BLOB OF MATTER or HUMAN BODY IS A PIECE OF MEAT, illustrated by the following text fragment of V. Woolf's novel "The Waves":

"We grew; we changed; for, of course, we are animals. We are not always aware by any means; we breathe, eat, sleep automatically. We exist not only separately but in undifferentiated blobs of matter." (Woolf, 2000: 246).

It is evident, that human bodies stand out in this context as undifferentiated from one another, having no defined limits. The corporeal aspect of a human being becomes a salient one as far as the latter appears as flesh only which at the same time appears as a tiny element in a mass of similar beings without identification. The society of people is viewed as a unified biomass, where the frontiers of separate bodies are erased or become dissolved as insignificant.

Such vision of the BODY implies a state of discomfort of mind and soul and presupposes the erosion of human individuality, its absorption by the crowd.

Similar meaning is activated in the novel "Between the Acts", where HUMAN BODY is interpreted as a formless "scrap of a society", generalized with the help of the conceptual metaphor HUMAN BODIES ARE FRAGMENTS, ORTS, SCRAPS OF SOCIETY / CIVILIZATION, compare:

Look at ourselves, ladies and gentlemen! Then at the wall; and ask how's this wall, the great wall, which we call, perhaps miscall, 
civilization, to be built by (here the mirrors flicked and flashed) orts, scraps and fragments like ourselves?" (Woolf, 1970: 394).

The idea of NON-INTEGRAL BODY is realized here in a wider context of a society or even civilization, individual HUMAN BODY being its fragment. Such figurative extension of the HUMAN BODY, obviously, highlights the ability of a human being to exist only as a part of the whole, losing itself when out of a civilized society. In the given poetic interpretation only society as a whole possesses integrity and continuity, whereas separate human beings, viewed through the prism of their corporeality, are the scraps of this complete system - metaphorically formless and having no clear boundaries when disconnected.

The meaning 'loss or violation of integrity' of a HUMAN BODY is activated in the following fragment of the text as well: "There is, then, a world immune from change. But I am not composed enough, standing on tiptoe on the verge of fire, still scorched by the hot breath, afraid of the door opening and the leap of the tiger, to make even one sentence. What I say is perpetually contradicted." (Woolf, 2000: 107). HUMAN BODY which is "not composed enough' stands here for 'being at a loss' of a novel character.

In a nutshell, the analyzed text fragments of V. Woolf's literary prose accentuate the obscurity of body limits, characteristic of the concept of HUMAN BODY in modernist philosophy, that found the corresponding metaphorical representation.

\section{Unified Body}

Another inherent feature of a HUMAN BODY ascribed by the modernist writer is open or erased limits. This quality is activated by means of the conceptual metaphor ONE'S HUMAN BODY IS THE HUMAN BODY DISSOLVED IN OTHER'S. It finds evidence in the fragment of V. Woolf's novel "The Waves":

Our friends, how seldom visited, how little known - it is true; and yet, when I meet an unknown person, and try to break off, here at this table, what I call "my life", it is not one life that I look back upon; I am not one person; I am many people; I do not altogether know who I am - Jinny, Susan, Neville, Rhoda, or Louis; or how to distinguish my life from theirs (Woolf, 2000: 276).

In this context the interpretation of the HUMAN BODY focuses on the "erosion of the body limits", which is as if being dissolved in other people's bodies, finding embodiment in other personalities. Such inseparable merging of the bodies, though, does not imply the unity, mutual understanding or close relationship of people in the society in V. Woolf's vision. More likely it implies annihilating individual body, i.e. human individuality, in favor of stereotyped sameness and facelessness induced by the impact of social norms. 
That is why the body limits in metaphorical representation of the author seem unclear as unimportant.

Instead, the image of a UNIFIED SOCIAL BODY is created, which presupposes one's inability to separate one's own body from other people's bodies, constituting a single social body. This idea is formulated by V. Woolf more than once in the text of the same novel, compare:

Yet how painful to be recalled, to be mitigated, to have one's self adulterated, mixed up, become part of another. As he approaches I become not myself but Neville mixed with somebody — with whom? - with Bernard? Yes, it is Bernard, and it is to Bernard that I shall put the question, Who am I?" (Woolf, 1970: 83); "To me at least it was indicated that we are members one of another. Each is part of the whole. Yes, that occurred to me, sitting among you in the audience (Woolf, 1970: 397).

The author focuses on one's body shared with others, being part of someone else's body, having presence in other bodies up to losing one's self (we are members one of another ... each is part of the whole) that results in feeling adulterated (how painful ... to have one's self adulterated, mixed up, become part of another).

Such erosion of corporeal boundaries due to body's merging with other's implies over against the articulated gap of detachment between people in the society and puts the accent on people losing their selves.

Besides, the image of the BODY WITHOUT LIMITS is created in the metaphoric space of V. Woolf's literary texts by means of activating the sense 'unstable limits' that contributes to the formation of the image of a DEFORMED BODY.

\section{Deformed Body}

V. Woolf frequently employs figurative deformations of the body in the imagery space of her literary texts, which occur as a result of metaphorical changes in the initial natural dimensions (size) of the body that mostly appear as its diminution or contraction.

Thus, the following fragment of the text illustrates the implication of the image of a DEFORMED BODY - of a SMALL (MINUTE) BODY, activating the conceptual metonymy MINUTE BODY stands for MISERABLE, DETACHED PERSON, e.g.: "Great clouds always changing, and movement; something sulphurous and sinister, bowled up, helter-skelter; towering, trailing, broken off, lost, and I forgotten, minute, in a ditch." (Woolf, 2000: 239).

The image of a CONTRACTED BODY, based on the identical principle of figurative diminishing of a HUMAN BODY, is employed by the author in the given text fragment: 
The cold stream of visual impressions failed him now as if the eye were a cup that overflowed and let the rest run down its china walls unrecorded. The brain must wake now. The body must contract now, entering the house, the lighted house, where the door stood open, where the motor cars were standing, and bright women descending: the soul must brave itself to endure. He opened the big blade of his pocket-knife (Woolf, 2010: 119).

Obviously, the implication of the conceptual metonymy CONTRACTED BODY stands for OPPRESSED PERSON serves in the abovementioned context to focus the oppressing impact of the society, imposing the unlimited number of constraints on a human being, that finds realization in the figurative changes of the body limits by means of either 'contraction' or 'diminution', which the body has to suffer in order to enter the society of people and spend some time among them (the body must contract now, entering the house).

The image of a DEFORMED BODY is employed by $\mathrm{V}$.Woolf in the context of literary semantics to signify the disappointed, depressed state of an individual.

For instance, in the following fragment of the text the conceptual metonymy DEFORMED BODY stands for DISAPPOINTED PERSON is applied in the novel "Mrs. Dalloway", where V. Woolf depicts the BODY of a person (of Mrs. Dalloway) who feels rejected by the society, being not invited to the party, as 'shrivelled'. Compare:

She began to go slowly upstairs, [...] she thought, feeling herself suddenly shrivelled, aged, breastless, the grinding, blowing, flowering of the day, out of doors, out of the window, out of her body and brain which now failed, since Lady Bruton, whose lunch parties were said to be extraordinarily amusing, had not asked her (Woolf, 2010: 23).

Not only figurative changes in the dimensions of the BODY, but its consistency as well contribute to the formation of the image of the BODY WITHOUT LIMITS in V. Woolf's literary prose by means of activation of the sense 'changeable limits'.

In the analyzed corpus of texts the process of altering the consistency of the BODY in the majority of contexts is associated with its melting, thawing, dissolving and other modification of corporeal structure up to attainment of transparency that also makes the vision of the body limits indefinite.

For example, this fact can be observed in the fragment of V. Woolf's novel, where the conceptual metaphor HUMAN BODY IS A WAXEN FIGURE is activated: 
"Month by month things are losing their hardness; even my body now lets the light through; my spine is soft like wax near the flame of the candle. I dream; I dream." (Woolf, 2000: 45).

Here HUMAN BODY is depicted with a spine made of wax that melts near the flame of the candle (my spine is soft like wax near the flame of the candle), and the entire body loses its solidity, is softened and becomes transparent (things are losing their hardness; even my body now lets the light through).

The change in the body consistency is used in the imagery space of $\mathrm{V}$. Woolf's literary prose to focus the devastating impact of social norms and institutes on the mind and soul of the individual.

Metaphorically, HUMAN BODY is described in the literary text of the novel "The Waves" as covered by wax coat that melts over time and causes the change of the "shape" of the BODY. Thus, the impact of social factors becomes obvious as figurative "melting" of the wax coat, e.g.:

But we were all different. The wax - the virginal wax that coats the spine melted in different patches for each of us. [...] our white wax was streaked and stained by each of these differently. Louis was disgusted by the nature of human flesh; Rhoda by our cruelty; Susan could not share; Neville wanted order; Jinny love; and so on. We suffered terribly as we became separate bodies (Woolf, 2000: 241).

From the fragment above is it obvious, that over time this "wax coat" melts in different patches for each person depending on their life experience and falls drop by drop. In such a way V. Woolf interprets the course of "wasting" the BODY away as the reaction of people to life troubles, compare: "Thus, not equally by any means or with order, but in great streaks my waxen waistcoat melted, here one drop, there another." (Woolf, 2000: 271); "It is not age; it is that a drop has fallen; another drop. Time has given the arrangement another shake." (Woolf, 2000: 271).

Eventually, the literary image of the BODY with changeable limits is applied by the modernist writer to accentuate human vulnerability and liability to suffer as a result of hard life experience and oppressive impact of the society on an individual.

\section{"Watery" Body}

Quite often figurative changes in the shape of the body or its undefined lineaments appear with the attainment of "watery" consistency.

For instance, in V. Woolf's novel "To the Lighthouse" HUMAN BODY is figuratively represented through the prism of the image of a MIST. This direction of imagery conceptualization is generalized with the help of the 
conceptual metaphor HUMAN BODY (FLESH) IS A MIST and illustrated with the text fragment:

Lily Briscoe knew all that. Sitting opposite him, could she not see, as in an X-ray photograph, the ribs and thigh bones of the young man's desire to impress himself, lying dark in the mist of his flesh — that thin mist which convention had laid over his burning desire to break into the conversation? (Woolf, 1994: 66).

Here the BODY through the implication of the conceptual metaphor HUMAN BODY (FLESH) IS A MIST that presupposes figurative loss of definite lineaments activates the meaning 'concealing the desires and ambitions and complicating the process of communication between people'. As well as the MIST is shapeless, equally the image of the BODY which is as obscure as a MIST, i.e. having no defined lineaments or silhouette, stands in the literary semantics for the person who is incomprehensible, obscure for understanding in communication, remaining a mystery for the social environment.

It is a well-known fact that human body consists mostly of water that sustain far from random choice of aquatic images as metaphorical correlates of the HUMAN BODY that accentuate its obscure nature and focus the will-less, faceless, vulnerable and suffering nature of a human being.

These mental and psychological states and features of an individual, emphasized through the corporeal aspects of undefined character are most brightly highlighted by means of the image of the BODY, which figuratively changes the physical conditions of its "water" - by turning "water" to "mist" or "freezing" it to "ice".

V. Woolf applies it to depict psychological sufferings of Septimus Smith in the text of the novel "Mrs. Dalloway", e.g.: "It was the heat wave presumably, operating upon a brain made sensitive by eons of evolution. Scientifically speaking, the flesh was melted off the world. His body was macerated until only the nerve fibres were left. It was spread like a veil upon a rock" (Woolf, 2010: 51), where the BODY not only "thaws", and the 'flesh melts off the world', but is 'macerated until only the nerve fibres were left' and remains 'spread like a veil upon a rock.

This modus of literary extension focuses the detachment of the person, who is exhausted because of constant physical and mental efforts aimed at the search of his place in the world that were unsuccessful and ended in his committing suicide.

In another fragment of the novel "The Waves" HUMAN BODY is reconsidered as a piece of ICE (HUMAN BODY IS AN ICE FLOE), that thaws and turns to a flow, stream of water, compare:

There is some check in the flow of my being; a deep stream presses on some obstacle; it jerks; it tugs; some knot in the centre resists. Oh, this is pain, this is anguish! I faint, I fail. Now my body thaws; I am unsealed, I am incandescent. Now the stream pours in a deep 
tide fertilizing, opening the shut, forcing the tight-folded, flooding free. To whom shall I give all that now flows through me, from my warm, my porous body? I will gather my flowers and present them —Oh! to whom? (Woolf, 2000: 57).

Here the BODY is, as if, deprived of rigid structure, it not only thaws (my body thaws), but also becomes "porous", permeable, letting the stream of water flow through it (now flows through me, from my warm, my porous body), that metaphorically designate human vulnerability, its susceptibility to negative social impact.

The meaning "will-less, driven person" of the BODY with "obscure limits" is activated in the following context, where it is conceptualized through the prism of the metaphor HUMAN BODY IS A FOAM, compare: "I am the foam that sweeps and fills the uttermost rims of the rocks with whiteness; I am also a girl, here in this room" (Woolf, 2000: 107).

The same metaphorical correlate (HUMAN BODY IS A FOAM) is applied to HUMAN BODY in V. Woolf's prose repeatedly:

But there is no single scent, no single body for me to follow. And I have no face. I am like the foam that races over the beach or the moonlight that falls arrowlike here on a tin can, here on a spike of the mailed sea holly, or a bone or a half-eaten boat. I am whirled down caverns, [...] (Woolf, 2000: 130).

In this text fragment the unguided character of the HUMAN BODY as well as FOAM moving over the waves (I am whirled down) implies uncertainty and inability of an individual to find his place in the society.

Other aquatic images selected by V. Woolf as metaphorical correlates of the HUMAN BODY, which figuratively imply its "watery consistency" and, thus, obscure lineaments, include the images of a WATER (LIQUID), WAVE, RIVER, STREAM, etc.

Thus, HUMAN BODY metaphorically acquires liquid and watery consistency in a number of contexts, e.g.:

All is soft, and bending. Walls and cupboards whiten and bend their yellow squares on top of which a pale glass gleams. Out of me now my mind can pour" (Woolf, 2000: 28);

The torments, the divisions of your lives have been solved for me night after night, sometimes only by the touch of a finger under the table-cloth as we sat dining - so fluid has my body become, forming even at the touch of a finger into one full drop, which fills itself, which quivers, which flashes, which falls in ecstasy (Woolf, 2000: 221). 
The modus of conceptualization, generalized by the conceptual metaphor HUMAN BODY IS A WATER (LIQUID) CONTAINER, highlights unstable, altering psychological state and changeable moods of an individual.

Watery and flowing character of a HUMAN BODY is evident in the text fragments, where the conceptual metaphor HUMAN BODY IS A RIVER, STREAM is activated, compare:

'They are very young. They are anxious to make a good impression. I feel a thousand capacities spring up in me. I am arch, gay, languid, melancholy by turns. I am rooted, but I flow. All gold, flowing that way, I say to this one, "Come." [...]. He approaches. He makes towards me. This is the most exciting moment I have ever known. I flutter. I ripple. I stream like a plant in the river, flowing this way, flowing that way, but rooted, so that he may come to me (Woolf, 2000: 103).

Even though the BODY seems to be well rooted, it flows (I am rooted, but I flow, I stream like a plant in the river, flowing this way, flowing that way, but rooted), as well as everything around (All gold, flowing that way). In such imagery representation HUMAN BODY appears not only as metaphorically "deprived of definite limits", but also as quick as a stream or river, that highlights the psychological instability of the characters, their lack of balance.

The author refers to the same literary image to accentuate the similar states of a human soul in other fragments of her novels, where the BODY is depicted as changing its consistency to a liquid one.

For example, in the following text fragment the BODY acquires watery consistency under the impact of sexual desire:

"Our bodies, his hard, mine flowing, are pressed together within its body; it holds us together; and then lengthening out, in smooth, in sinuous folds, rolls us between it, on and on." (Woolf, 2000: 103).

Here the image of the BODY that loses solidity and definite boundaries also serves for the figurative interpretation of the corresponding mental and spiritual states.

Sometimes the HUMAN BODY is metaphorically equaled to the single and unified water space, the image of the SEA being applied to the SOCIETY, whereas the image of the WAVE - to the HUMAN BODY, compare:

"Sunk for a long time in profound thoughts as to the value of obscurity, and the delight of having no name, but being like a wave which returns to the deep body of the sea; thinking how obscurity rids the mind of the irk of envy and spite ..." (Woolf, 2006: 77).

The context illustrates the implication of the image of the "limitless" BODY in the most articulated form activating the conceptual metaphor 
HUMAN BODY IS A WAVE. On the one hand, the changeable shape of its metaphorical correlate - the WAVE - implies the same characteristics of the BODY, on the other - HUMAN BODY alongside other BODIES constitute a single unified water space (SOCIETY IS THE SEA), thus, becoming inseparable part of the whole.

Corporeal image of the BODY which has open and indefinite limits that fail to fulfill the function of separating one BODY from another in space contributes to the formation of V. Woolf's vision of the society where people are standardized - faceless, nameless, will-less and follow the same "rules" as they follow the stream (the value of obscurity, and the delight of having no name). As the sea engulfs water drops, streams, rivers, waves, etc., the society "consumes" personal wills, desires, specific traits, instead creating the society of people who think and feel alike. In such interpretation 'being not separated physically', apparently, stands for the 'inclusion into the unified mental space of the society'.

In a nutshell, unstable, obscure, open and permeable BODY limits stand for psychological vulnerability, liability to depression, detachment, despair and suchlike. Being physically not delimited in the imagery space of the literary text, an individual appears open and susceptible to mental and psychological suffering and devastating, oppressive impact of the socialization process.

\section{Invisible Body}

Finally, among the figurative means that accomplish V. Woolf's poetic vision of the HUMAN BODY, namely BODY WITHOUT LIMITS, there are the images characterized by the utmost incorporeity or the absence of limits.

Quite often the author appeals to the image of INVISIBLE BODY by means of the images of a GHOST or a PHANTOM. Absolute "loss of corporeity" in her figurative interpretation, apparently, implies psychological emptiness, disappointment and detachment which are hardly noticed by the social environment, as far as human being is nothing but a BODY which is not visible, a PHANTOM, compare:

But without Percival there is no solidity. We are silhouettes, hollow phantoms moving mistily without a background (Woolf, 2000: 122); Upon which, wearily, ghostlily, as if they had feather-light fingers and the light persistency of feathers, they would look, once, on the shut eyes, and the loosely clasping fingers, and fold their garments wearily and disappear (Woolf, 1994: 94).

The author explains such perception of the body by lonely state of mind. Not only the body, but all objects around lose solidity when someone you need to be close is away (without Percival there is no solidity). Such "losing limits" up to "losing visibility" highlights mental suffering of an individual and his detachment. 
In V. Woolf's interpretation of human relationships even friendship does not bring mutual understanding and true closeness. It that is obvious from the context, activating the conceptual metaphor HUMAN BODY IS A PHANTOM:

«Our friends - how distant, how mute, how seldom visited and little known. And I, too, am dim to my friends and unknown; a phantom, sometimes seen, often not. Life is a dream surely." (Woolf, 2000: 275).

Even being physically close, people remain figuratively "invisible" (I, too, am dim to my friends and unknown; a phantom, sometimes seen, often not), i.e. unknown to each other.

\section{Conclusion}

In a nutshell, the image of the BODY WITHOUT LIMITS, realized in V. Woolf's literary prose by means of the images of NON-INTEGRAL BODY, UNIFIED BODY, DEFORMED BODY, "WATERY" BODY and INVISIBLE BODY is employed to depict the state of mind and soul of an individual in the social environment, where figurative "losing body limits" stands for "mental vulnerability" and "losing psychological balance" caused by the processes of socialization. Such figurative "transformations" of the BODY under the influence of socio-cultural factors in the literary semantics of modernist prose implying depressed state of mind reveal the characteristics that are specific of the modernist period.

\section{References}

Barthes, R. 1989. Semiotics: Poetics. Moscow: Progress.

Deleuze, G., Guattari, F. 1972. Capitalisme et schizophrénie. L'Anti-CEdipe. Les Editions De Minuit.

Fauconnier, G., Turner M. 2003. The Way We Think: Conceptual Blending And The Mind's Hidden Complexities. NY: Basic Books.

Foucault, M. 1970. The Order of Things. London: Tavistock.

Foucault, M. 1977. Discipline and Punish. London: Allen Lane.

Foucault, M. 1978. An Introduction. Vol. 1 of The History of Sexuality. New York: Pantheon.

Gibbs, R. 2006. Embodiment and cognitive science. Cambridge: Cambridge University Press.

Galutskikh, I. 2013. Human Body in the Society: The View through the Prism of Literary Corporality. International Journal of Social Science and Humanity. Vol. 3, No. 3, 237-241.

Husserl, E. 1982. Ideas Pertaining to a Pure Phenomenology and to a Phenomenological Philosophy. The Hague: Nijhoff.

Kövecses, Z. 2002. Metaphor: A Practical Introduction. Oxford: OUP. 
Lakoff, G., Johnson M. 1980. Metaphors We Live by. Chicago: University of Chicago Press.

Merleau-Ponty, M. 1999. Phenomenologija vosprijatija. SPb.: Nauka; Juventa.

Nancy, J.-L. 2008. Corpus. Fordharm University Press.

Otsry, M.V. 2008. Problema telesnosti v zapadnom iskusstve XX veka: ontologicheskij aspect. - The Problem of Corporeality in the Eastern Art of the XXth century. Unpublished PhD thesis. Samara, Russia.

Pease, A. 1981. Body language: how to read others' thoughts by their gestures. Sheldon Press.

Woolf, V. 1970. Between the Acts. London: Mariner Books.

Woolf, V. 2010. Mrs. Dalloway. A Room of One's Own. Houghton Mifflin Harcourt.

Woolf, V. 2006. Orlando. London: Mariner Books.

Woolf, V. 2000. The Waves. London: Wordsworth Editions.

Woolf, V. 1994. To the Lighthouse. Hertfordshire: Wordsworth Editions Ltd.

Ziemke, T. et al. 2007. Body, Language and Mind. Vol.1: Embodiment. Berlin, NY: Mouton de Gruyter. 
